\title{
Effects of the Antianginal Drug Trapidil on Atrioventricular Conduction Disturbances During Acute Myocardial Ischemia
}

\author{
Ichiro Watanabe, ${ }^{1} \mathrm{MD}$, Yasuo OKumura, ${ }^{1} \mathrm{MD}$, Koichi Nagashima, ${ }^{1} \mathrm{MD}$, \\ Masayoshi Kofune, ${ }^{1}$ MD, Kimie OHKubo, ${ }^{1}$ MD, Hiroaki Mano, ${ }^{1}$ MD, \\ Kazuyuki Sonoda, ${ }^{1}$ MD, Yuji Kasamaki, ${ }^{1} \mathrm{MD}$, and Atsushi Hirayama, ${ }^{1}$ MD
}

\begin{abstract}
SUMMARY
Adenosine and related compounds have been shown to produce atrioventricular (AV) conduction block during acute myocardial ischemia. We investigated the effects of the antianginal drug trapidil, which has been shown to inhibit phosphodiesterase, on AV conduction disturbances in a canine model of acute myocardial ischemia. In 35 anesthetized dogs, the AV node artery was cannulated and perfused with arterial blood. Adenosine (300 $\mu \mathrm{g}, 650 \mu \mathrm{g}$, or $1000 \mu \mathrm{g}) \mathrm{was}$ injected into the AV node artery. With administration of adenosine at $300 \mu \mathrm{g}, 650 \mu \mathrm{g}$, or $1000 \mu \mathrm{g}$, the atrio-His (AH) interval was increased by $14.6 \mathrm{~ms}, 22.3 \mathrm{~ms}$, and $29.7 \mathrm{~ms}$, respectively. The effects of adenosine were potentiated by pretreatment with intravenous dipyridamole $(250 \mu \mathrm{g} / \mathrm{kg})$, an inhibitor of adenosine uptake, but the effects of adenosine were attenuated with intravenous trapidil $(3 \mathrm{mg} / \mathrm{kg})$, an inhibitor of phosphodiesterase. AV node artery occlusion resulted in prolongation of the $\mathrm{AH}$ interval in 4 of 12 dogs. The ischemia-induced $\mathrm{AH}$ prolongation was potentiated with intravenous dipyridamole and attenuated with intravenous trapidil. AV conduction disturbances associated with inferior myocardial infarction may be related in part to endogenously released adenosine, and trapidil may be useful in treating AV block associated with acute AV node ischemia. (Int Heart J 2012; 53: 187-192)
\end{abstract}

Key words: Atrioventricular block, Acute myocardial ischemia, Adenosine, Dipyridamole, Trapidil

$\mathrm{T}$ he electrophysiologic effects of adenosine (ADO) and other adenine derivatives were first described by Drury and Szent-Gyorgi in $1929,{ }^{1)}$ who clearly demonstrated that intravenous administration of adenosine produced a decrease in sinus rate and transient atrioventricular (AV) block. Adenosine was found to be a mediator of many physiologic phenomena, and most of the interest in its effects on the cardiovascular system were centered on its ability to regulate regional blood flow in the heart and other organs. In the 1980s, several investigators reexamined the electrophysiologic effects of adenosine. ${ }^{2,3)}$ Belardinelli, et al showed that adenosine produced various degrees of dose-related reversible AV block in guinea pig and rabbits hearts perfused by the Langendorff technique, and the negative dromotropic effects were localized to $\mathrm{AV}$ nodal tissue. ${ }^{3,4)}$ Of interest was the finding that when $\mathrm{AV}$ nodal conduction was impaired by an intervention such as hypoxia or ischemia, which caused increased release of adenosine from myocardial cells, the AV conduction delay and block were similar to those caused by exogenous adenosine. ${ }^{4,5)} \mathrm{Hy}-$ poxia in isolated perfused mammalian heart ${ }^{4}$ or ischemia of the AV node (by ligation of the AV node artery) in canine heart in situ ${ }^{6}$ caused prolongation of the $\mathrm{AH}$ interval that often resulted in second-degree AV block. The fact that the hypoxia- or ischemia-induced $\mathrm{AV}$ conduction block could be modified in a predictable manner by interventions known to antagonize and/ or potentiate the actions of adenosine lends support to the con- cept that the dromotropic effects of hypoxia and ischemia are mediated by adenosine release from oxygen-deprived myocardial cells. ${ }^{3,46)}$ Dipyridamole (a drug that protects against adenosine degradation by blocking its uptake into cells and hence its deamination to inosine) potentiates and methyxanthines (competitive adenosine antagonists) attenuate hypoxia- and ischemia-induced $\mathrm{AH}$ prolongation and $\mathrm{AV}$ block.-8)

Trapidil, 5-methyl-7-diethyamino-s-triazolo [1, 5-a] pyrimidine, is an antianginal drug that is reported to have many pharmacological and biochemical actions within the circulatory system of animals; producing dilatation of large coronary arteries and collateral pathways;, ${ }^{, 10)}$ increasing development of interarterial coronary anastomoses ${ }^{11}{ }^{11}$ inhibiting phosphodiesterase activity ${ }^{12)}$ platelet aggregation; and the action or synthesis of thromboxane $\mathrm{A}_{2},{ }^{13)}$ and facilitating prostacyclin synthesis. ${ }^{9}$ Trapidil has also been shown to decrease myocardial infarct size in dogs. ${ }^{14)}$ The objective of the study described herein was to investigate the effects of trapidil on the AV conduction disturbance accompanying myocardial ischemia in an in situ heart preparation.

\section{Methods}

Animal preparation: Thirty-five mongrel dogs weighing 14$35 \mathrm{~kg}(20.0 \pm 4.9 \mathrm{~kg})$ were used in the study. The animals were

From the ${ }^{1}$ Division of Cardiology, Department of Medicine, Nihon University School of Medicine, Tokyo, Japan.

Address for correspondence: Ichiro Watanabe, MD, Division of Cardiology, Department of Medicine, Nihon University School of Medicine, 30-1 Oyaguchi-kamimachi, Itabashi-ku, Tokyo 173-8610, Japan.

Received for publication July 25, 2011.

Revised and accepted March 1, 2012. 
cared for according to the position of the American Heart Association on the use of research animals, along with accepted guidelines for the care and treatment of experimental animals at Nihon University School of Medicine. The dogs were immobilized with intramuscular ketamine $(15 \mathrm{mg} / \mathrm{kg})$ and anesthetized with intravenous pentobarbital sodium $(25 \mathrm{mg} / \mathrm{kg})$. Anesthesia was maintained with pentobarbital sodium (100 $\mathrm{mg}$ ) as needed. A surface electrocardiogram (lead II) was continuously monitored throughout the experiments. The dogs were intubated and placed on a volume-controlled animal ventilator (Model 613; Harvard Apparatus, South Natick, MA, USA). Intravenous Ringer's solution was infused as needed to replace lost fluid through a $6 \mathrm{~F}$ sheath placed in the left femoral vein. Arterial blood pressure was continuously monitored by polygraph (MCI-9800; Fukuda Denshi Co., Ltd., Tokyo) via a catheter positioned in the aorta via the right femoral artery. Under controlled ventilation, right thoracotomy was performed at the fourth intercostal space, and the heart was exposed by pericardiotomy. For selective perfusion of the AV node region, the technique developed by Nadeau and Amir-Jahed was used. ${ }^{15)}$ In brief, the AV node artery (ANVA), a distal branch of the left circumflex coronary artery, was carefully dissected, and sutures were placed around it. The AVNA was then cannulated with a small polyethylene tube, and the tube was connected to a polyvinyl catheter placed in the left carotid artery to perfuse the AVNA with arterial blood (Figure 1). If the AVNA was too small to cannulate, another posteroseptal artery was used. Systemic intravenous administration of heparin (100 $\mathrm{U} / \mathrm{kg}$, followed by $20 \mathrm{U} / \mathrm{Kg} /$ hour) was started. To confirm that the cannulated artery was perfusing the AV node, acetylcholine $(2 \mathrm{~mL}, 0.1 \mu \mathrm{g} / \mathrm{mL}$ ) was injected from the cannulated artery, and the dogs that showed transient complete AV block were used in the study. The sinus node was crushed, and electrical pacing at 150 beats/minute was applied to the right atrium via a bipolar hook electrode with a cardiac stimulator (BC-02; Fukuda Denshi Co., Ltd.). Right atrial and ventricular electro-

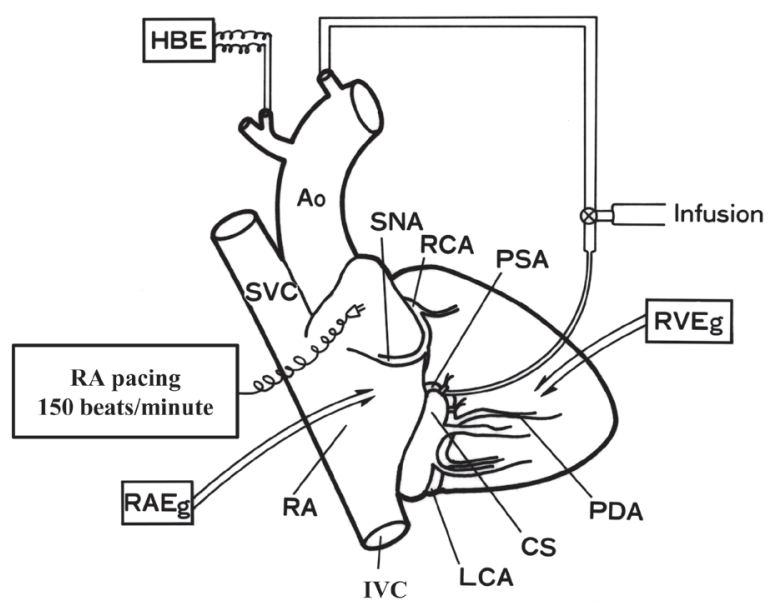

Figure 1. Diagram of the electrophysiologic testing. HBE indicates His bundle electrogram; RA, right atrium; CS, coronary sinus; IVC, inferior vena cava; LCA, left circumflex coronary artery; PDA, posterior descending coronary artery; RCA, right coronary artery; SNA, sinus node artery; PSA, posteroseptal coronary artery; Ao, aorta; SVC, superior vena cava; $\mathrm{RAEg}$, right atrial electrogram; and RVEg, right ventricular electrogram. grams were recorded by bipolar plunge electrodes, ie, Tefloncoated stainless wires (0.0045-inch diameter) inserted into the right atrium and right ventricle with the use of 23-gauge needles. ${ }^{16)}$ A His bundle electrogram was obtained with a $6 \mathrm{Fr}$ quadripolar electrode catheter (BARD Electrophysiology, Lowell, MA, USA) having 1-cm interelectrode spacing. The catheter was introduced into the aorta via the right carotid artery and then advanced under manual control into the ascending aorta and finally wedged in the noncoronary cusp of the aortic valve. ${ }^{17)}$ The lead II electrocardiogram signal and signals from the catheter were amplified and displayed on the polygraph and recorded on an optical recorder (Rapicorder RVM 540A; Kyowa Dengyo Inc., Tokyo) at a paper speed of 100 $\mathrm{mm} / \mathrm{second}$.

Experimental protocol: The AVNA was occluded for $10 \mathrm{~min}-$ utes, and the acute myocardial ischemia resulted in prolongation of the AH interval in 5 of the 35 dogs. In 29 of the 30 dogs that did not show ischemia-induced prolongation of the $\mathrm{AH}$ interval, protocol 1 or 2 (described below) was applied. In the remaining dog that did not show AH prolongation and in the 5 dogs that did show AH prolongation during AVNA occlusion, protocol 3 (described below) was applied.

Protocol 1: Atrial-to-His bundle ( $\mathrm{AH}$ ) conduction time was measured before (baseline) and after all experimental interventions involving injection of adenosine (Sigma Chemical Co., St. Louis, MO, USA). Adenosine was dissolved in physiological salt solution to produce concentrations of $300 \mu \mathrm{g} / \mathrm{mL}, 650$ $\mu \mathrm{g} / \mathrm{mL}$, and $1000 \mu \mathrm{g} / \mathrm{mL}$. The adenosine was then infused into the AVNA as a bolus of $1 \mathrm{~mL}(300 \mu \mathrm{g} / \mathrm{mL}$ in $6 \mathrm{dogs}, 650 \mu \mathrm{g} /$ $\mathrm{mL}$ in $6 \mathrm{dogs}$, and $1000 \mu \mathrm{g} / \mathrm{mL}$ in $5 \mathrm{dogs}$ ). Each dose was injected in duplicate, and the responses were averaged (unless otherwise noted). Protocol 1a; dipyridamole (Nippon Boehringer Ingelheim Co., Ltd., Tokyo), an inhibitor of adenosine uptake, and protocol 1b; trapidil (Mochida Pharmaceutical Co. Ltd., Tokyo) were administered intravenously at $250 \mu \mathrm{g} / \mathrm{kg}$ and $3 \mathrm{mg} / \mathrm{kg}$, respectively. Then, each dose of adenosine was administered in duplicate. The ability of dipyridamole to potentiate and the ability of trapidil to attenuate the effects of adenosine were examined.

Protocol 2: Intravenous administration of dipyridamole (500 $\mu \mathrm{g} / \mathrm{kg}, n=4)$ or dipyridamole $(500 \mu \mathrm{g} / \mathrm{kg})$ and propranolol $(0.5$ $\mathrm{mg} / \mathrm{kg}, n=3$ ) was followed by injection of adenosine (1000

Table. AV Conduction (AH Interval) Under Three Successive Conditions (Protocol 2)

\begin{tabular}{cccc}
\hline Dog & Baseline & Saline & Trapidil \\
\hline 1 & $3: 2$ block & $3: 2$ block & $133 \mathrm{~ms}$ \\
2 & $2: 1$ block & - & $162 \mathrm{~ms}$ \\
3 & $10: 9$ block & $6: 5$ block & $130 \mathrm{~ms}$ \\
4 & $107 \mathrm{~ms}$ & - & $73 \mathrm{~ms}$ \\
$5^{*}$ & $166 \mathrm{~ms}$ & $163 \mathrm{~ms}$ & $137 \mathrm{~ms}$ \\
$6^{*}$ & $159 \mathrm{~ms}$ & - & $128 \mathrm{~ms}$ \\
$7^{*}$ & $3: 2$ block & $3: 2$ block & $103 \mathrm{~ms}$ \\
\hline
\end{tabular}

Protocol 2 = effects of intracoronary administration of trapidil on the intracoronary administration of adenosine (following intravenous administration of dipyridamole)-induced increase in AH interval or AV block. Baseline: after intracoronary administration of adenosine, Saline: intracoronary administration of saline following baseline condition, Trapidil: intracoronary administration of trapidil following saline administration. "These dogs were given propranolol. 
$\mu \mathrm{g})$ into the ANVA. After development of AV block, saline ( $n=2$ for dipyridamole group and $n=2$ for dipyridamole + propranolol group) followed by trapidil (dissolved in saline; $500 \mu \mathrm{g} / \mathrm{mL}$ for the dipyridamole group, $n=4$, or $1000 \mu \mathrm{g} / \mathrm{mL}$ for the dipyridamole + propranolol group, $n=3$ ) were injected into the AVNA (Table).

Protocol 3: In the 5 dogs with ischemia-induced prolongation of the $\mathrm{AH}$ interval, the $\mathrm{AH}$ interval returned to the baseline value by reperfusion. In another dog, the $\mathrm{AH}$ interval did not change markedly during ANVA occlusion. Fifteen minutes after reperfusion, dipyridamole $(250 \mu \mathrm{g} / \mathrm{kg}, n=3)$ or trapidil ( $3 \mathrm{mg} / \mathrm{kg}, n=3$ ) was administered intravenously, and the AVNA was occluded for 10 minutes. The $\mathrm{AH}$ interval during AVNA occlusion was compared before and after administration of the dipyridamole or trapidil. In another dog, trapidil was administered 10 minutes after AVNA occlusion.

Statistical analysis: Values are expressed as the mean \pm standard error of the mean. Changes in the $\mathrm{AH}$ interval (from the baseline value) were analyzed by Student's $t$ test. A $P<0.05$ was considered statistically significant. StatView 5.0 software (SAS Institute, Cary, NC, USA) was used for all statistical analyses.

\section{RESULTS}

Effects of intracoronary administration of adenosine on the $\mathrm{AH}$ interval: Twenty-two dogs were subjected to protocol 1. As shown in Figure 2, the baseline AH interval in these dogs was $78.6 \pm 4.6 \mathrm{~ms}$. With intracoronary administration of $300 \mu \mathrm{g}$, $650 \mu \mathrm{g}$, or $1000 \mu \mathrm{g}$ adenosine, the $\mathrm{AH}$ interval increased to $99.3 \pm 6.8 \mathrm{~ms}(P<0.01$ versus baseline $), 105.7 \pm 6.8 \mathrm{~ms}(P<$ 0.01 versus $300 \mu \mathrm{g}$ adenosine $)$, and $110 \pm 6.7 \mathrm{~ms}(P<0.01$

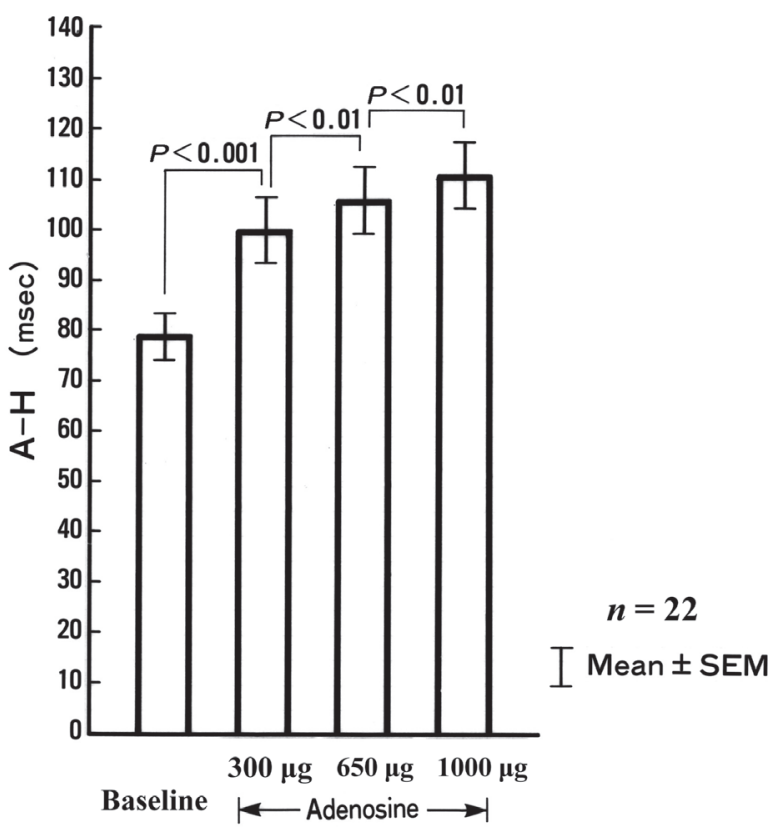

Figure 2. Effects of intracoronary injection of adenosine on the atrio-His (AH) interval. SEM indicates standard error of the mean. Baseline = before administration of adenosine. versus $650 \mu \mathrm{g}$ adenosine), respectively. Five dogs that showed Wenckebach-type AV block with administration of $300 \mu \mathrm{g}$ were excluded from the statistical analysis.

Effects of dipyridamole and trapidil on adenosine-induced $\mathrm{AH}$ prolongation: Eleven dogs were subjected to protocol 1a; (dipyridamole group). The baseline $\mathrm{AH}$ interval in these dogs was $67.7 \pm 6.7 \mathrm{~ms}$. The AH interval increased to $82.3 \pm 4.2 \mathrm{~ms}$ $(n=6, P=0.08), 90.0 \pm 5.0 \mathrm{~ms}(n=6, P<0.02)$, and $97.4 \pm$ $4.3 \mathrm{~ms}(n=5, P<0.001)$ with administration of $300 \mu \mathrm{g}, 650$ $\mu \mathrm{g}$, and $1000 \mu \mathrm{g}$ adenosine, respectively. Three dogs that showed Wenckebach-type AV block with administration of $300 \mu \mathrm{g}$ adenosine were excluded from the analysis. Two dogs showed Wenckebach-type AV block with administration of $300 \mu \mathrm{g}$ after dipyridamole administration and another dog developed Wenckebach-type AV block with administration of $1000 \mu \mathrm{g}$ adenosine after dipyridamole administration and were also excluded from the statistical analysis. The AH interval increased to $81.6 \pm 8.1 \mathrm{~ms}(n=11, P<0.001)$ with administration of dipyridamole. The AH interval increased to $116.3 \pm 6.2$

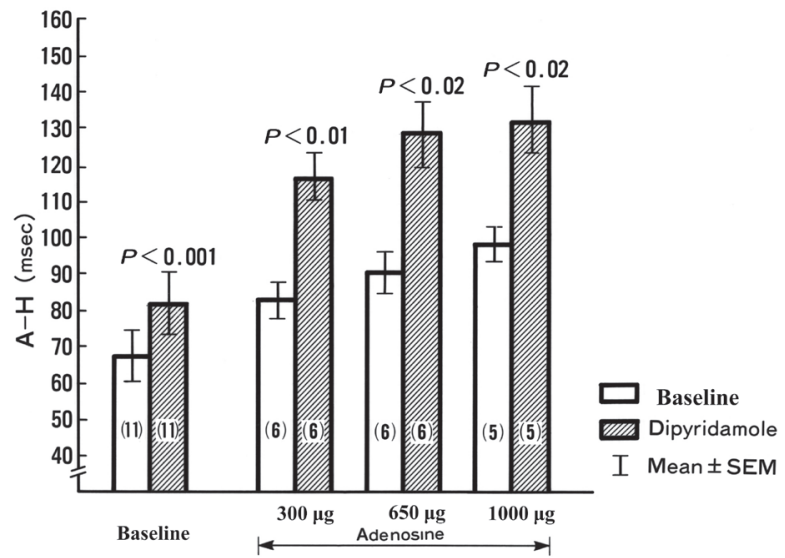

Figure 3. Effects of intravenous administration of dipyridamole on the intracoronary injection of adenosine-induced atrio-His (AH) interval prolongation. SEM indicates standard error of the mean. Baseline $=$ before administration of adenosine.

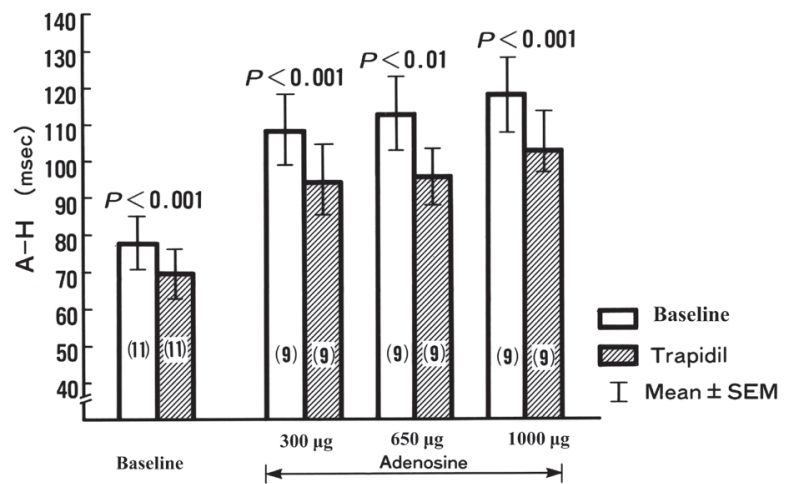

Figure 4. Effects of intravenous administration of trapidil on the intracoronary injection of adenosine-induced atrio-His (AH) interval prolongation. SEM indicates standard error of the mean. Baseline = before administration of adenosine. 


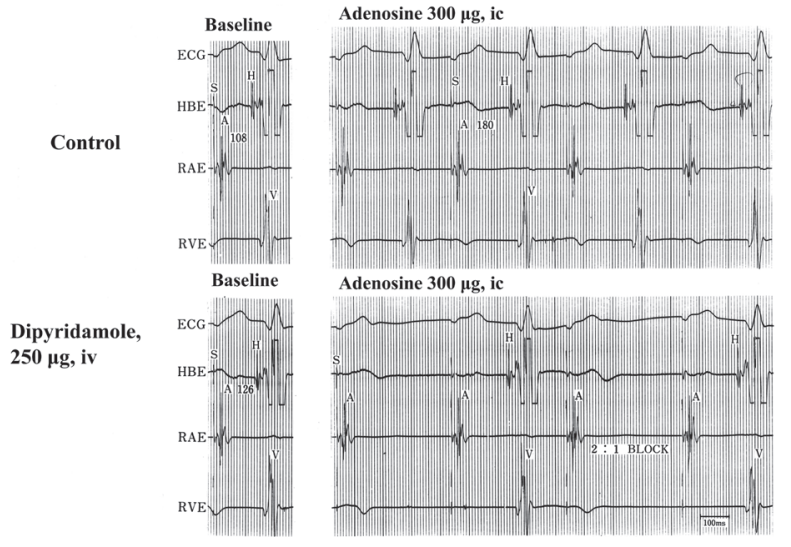

Figure 5. Effects of intravenous administration of dipyridamole on intracoronary injection of adenosine. Note that intracoronary injection of adenosine after intravenous administration of dipyridamole induced 2:1 $\mathrm{AH}$ block. Control indicates AH intervals before intravenous administration of dipyridamole; Baseline, $\mathrm{AH}$ intervals before administration of adenosine; ECG, surface electrocardiogram; HBE, His bundle electrogram; RAE, right atrial electrogram; RVE, right ventricular electrogram; S, pacing spike; A, local atrial potential; V, local ventricular electrogram; and $\mathrm{H}$, His bundle electrogram. Note in the upper left panel that the AH interval is $108 \mathrm{~ms}$; in the upper right panel the $\mathrm{AH}$ interval is $180 \mathrm{~ms}$; and in the lower left panel the AH interval is $126 \mathrm{~ms}$.

\section{2:1 AH block $300 \mu \mathrm{g}$ of adenosine, ic +500 $\mu \mathrm{g} / \mathrm{kg}$ of dipyridamole, iv}

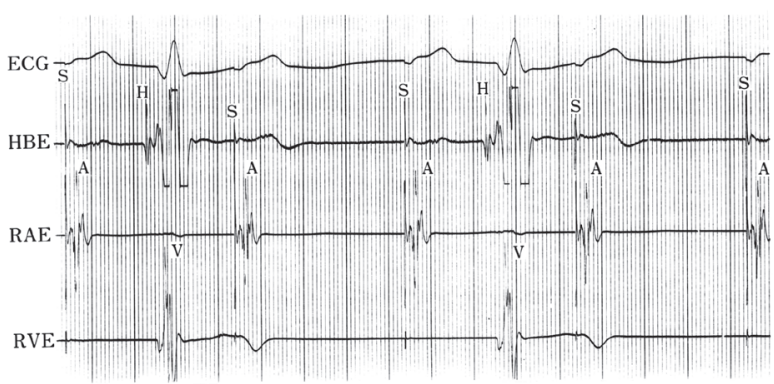

1 minute after $500 \mu \mathrm{g}$ of trapidil, ic

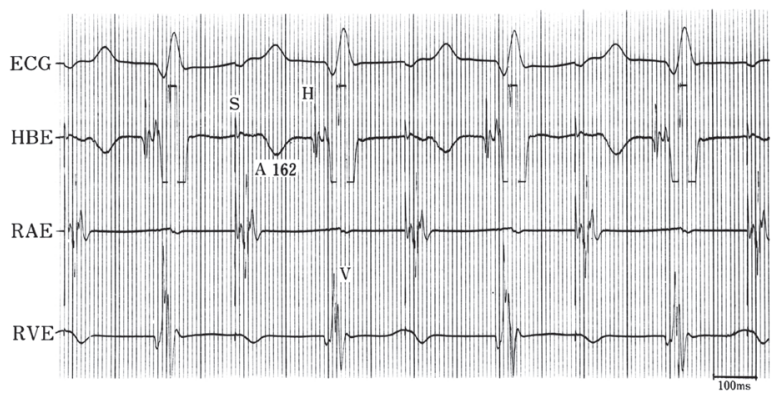

Figure 6. Effects of intracoronary injection of $500 \mu \mathrm{g}$ trapidil on 2:1 atrioHis block induced by intracoronary injection of $300 \mu \mathrm{g}$ adenosine after pretreatment with intravenous dipyridamole $(500 \mu \mathrm{g})$. Note that 2:1 atrioHis block was reversed by trapidil. ECG indicates surface electrocardiogram; HBE, His bundle electrogram; RAE, right atrial electrogram; RVE, right ventricular electrogram; $\mathrm{S}$, pacing spike; A, local atrial potential; V, local ventricular electrogram; H, His bundle electrogram; 162, atrio-His interval of $162 \mathrm{~ms}$; ic, intracoronary injection; and iv, intravenous administration.
( $n=6, P<0.01$ versus control), $128.3 \pm 8.8(n=6, P<0.02)$, and $131.6 \pm 9.1 \mathrm{~ms}(n=5, P<0.02)$ with administration of $300 \mu \mathrm{g}, 650 \mu \mathrm{g}$, and $1000 \mu \mathrm{g}$ adenosine, respectively (Figure 3). Another eleven dogs were subjected to protocol 1b (trapidil group). The baseline AH interval was $77.1 \pm 6.9 \mathrm{~ms}(n=11)$. The AH interval was increased to $107.2 \pm 9.9(n=9, P<0.03$ versus control adenosine $300 \mu \mathrm{g}), 112.9 .0 \pm 10.0(n=9, P<$ 0.02 versus control adenosine $650 \mu \mathrm{g}$ ), and $117.8 \pm 10.0 \mathrm{~ms}$ $(n=9, P<0.01$ versus control adenosine $1000 \mu \mathrm{g}$ ) with 300 $\mu \mathrm{g}, 650 \mu \mathrm{g}$, and $1000 \mu \mathrm{g}$ adenosine, respectively. With trapidil administration, the $\mathrm{AH}$ interval decreased to $69.8 \pm 7.0 \mathrm{~ms}$ ( $n=11, P<0.001)$. Two dogs that showed Wenckebach-type $\mathrm{AV}$ block with administration of $300 \mu \mathrm{g}$ adenosine were excluded from the analysis. With trapidil administration, the $\mathrm{AH}$ interval decreased to $94.4 \pm 9.5(n=9, P<0.001$ versus control adenosine $300 \mu \mathrm{g}), 95.6 \pm 7.7(n=9, P<0.01$ versus control $650 \mu \mathrm{g})$, and $103.0 \pm 10.1 \mathrm{~ms}(n=9, P<0.001$ versus control adenosine $1000 \mu \mathrm{g}$ ), with $300 \mu \mathrm{g}, 650 \mu \mathrm{g}$, and $1000 \mu \mathrm{g}$ adenosine, respectively (Figure 4).

Effects of trapidil on the AV nodal conduction disturbances by adenosine pretreated with dipyridamole, or dipyridamole plus propranolol: Seven dogs were subjected to protocol 2. In 4 dogs, dipyridamole administration followed by intracoronary administration of adenosine resulted in Wenckebach-type $(n=$ 2 ) or 2:1 AH block $(n=1)$ (Figure 5). In another 3 dogs, dipyridamole and propranolol administration followed by adenosine resulted in Wenckebach-type AH block in 1 dog. In 3 dogs with Wenckebach-type AH block, intracoronary administration of saline did not improve the AV conduction, but intracoronary administration of trapidil improved the AV conduction to 1:1. In another dog, which showed 2:1 AH block, conduction was also converted to 1:1 with trapidil administration (Figure 6). In 3 dogs that did not show Wenckebach-type $\mathrm{AH}$ block, the $\mathrm{AH}$

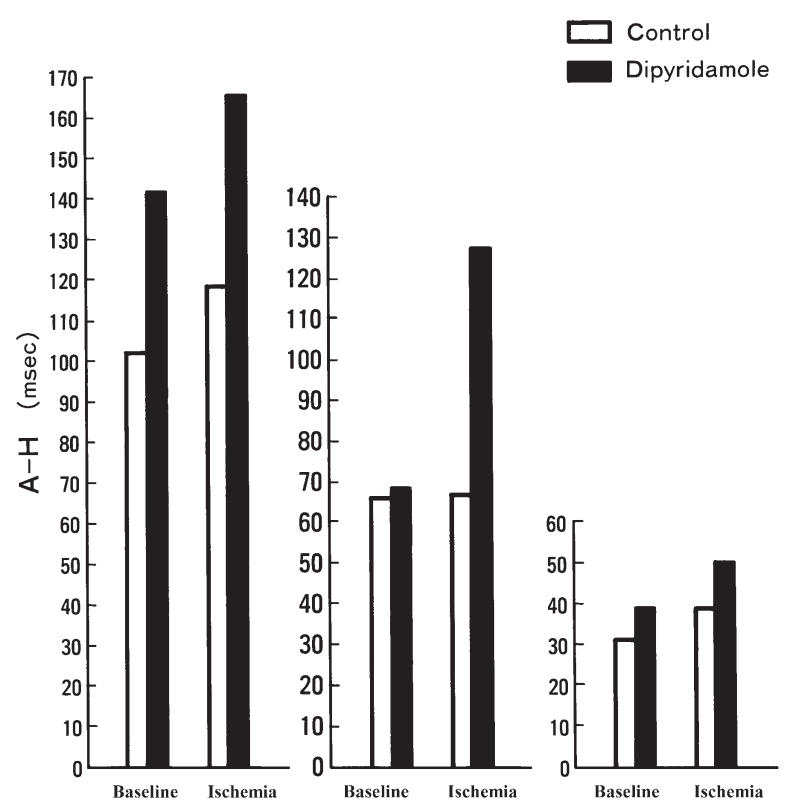

Figure 7. Effects of dipyridamole on the atrio-His interval during atrioventricular node artery (AVNA) occlusion. A-H indicates atrio-His interval; Control, before administration of dipyridamole; and Baseline, before AVNA occlusion. 

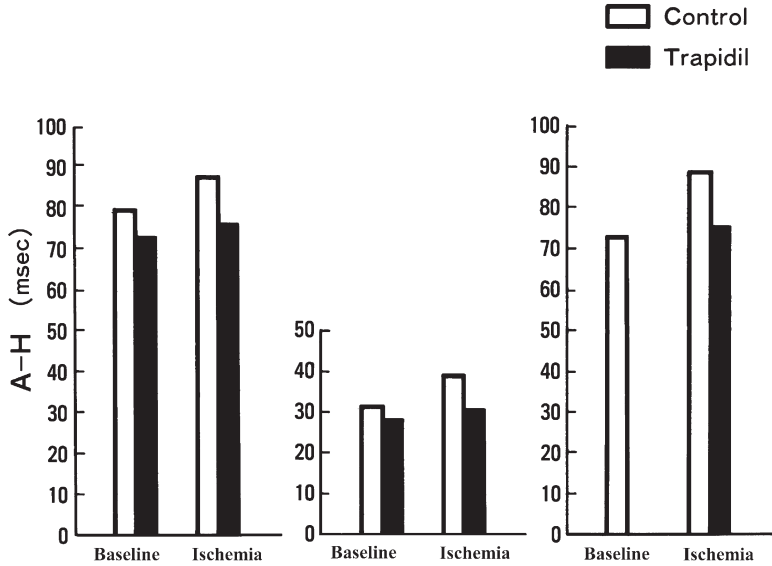

Figure 8. Effects of trapidil on the atrio-His interval during atrio-ventricular node artery occlusion. A-H indicates atrio-His interval; Control, before administration of trapidil; and Baseline, before AVNA occlusion.

interval was shortened with trapidil administration (Table). Effects of dipyridamole and trapidil on ischemia-induced AV conduction disturbances: Six dogs were subjected to protocol 3. The effect of dipyridamole on AV conduction during the 10-minute AVNA occlusion was evaluated. In the control condition, 2 dogs showed a change in the AH interval from 102 $\mathrm{ms}$ to $118 \mathrm{~ms}$ (Figure 7, left panel) or from $30 \mathrm{~ms}$ to $38 \mathrm{~ms}$ (Figure 7, right panel). In a third dog, the $\mathrm{AH}$ interval did not change markedly (from $66 \mathrm{~ms}$ to $67 \mathrm{~ms}$, Figure 7, middle panel) during ANVA occlusion. With dipyridamole, the AH interval increased by $40 \mathrm{~ms}$ and $45 \mathrm{~ms}$ (Figure 7, left panel), by 8 $\mathrm{ms}$ and $12 \mathrm{~ms}$ (Figure 7, right panel), and by $2 \mathrm{~ms}$ and $61 \mathrm{~ms}$ (Figure 7, middle panel) before and after AVNA occlusion.

The effect of trapidil on AV conduction during the 10-minute AVNA occlusion was evaluated in 3 dogs. In the control condition, 3 dogs showed a change in the AH interval from $79 \mathrm{~ms}$ to $86 \mathrm{~ms}$ (Figure 8, left panel), $31 \mathrm{~ms}$ to $38 \mathrm{~ms}$ (Figure 8, middle panel), or $73 \mathrm{~ms}$ to $89 \mathrm{~ms}$ (Figure 8, right panel) during ANVA occlusion. Trapidil decreased the AH interval by $6 \mathrm{~ms}$ and 11 $\mathrm{ms}$ (Figure 8, left panel) and by $3 \mathrm{~ms}$ and $7 \mathrm{~ms}$ (Figure 8, middle panel) before and after ANVA occlusion. In another dog, trapidil was administered 10 minutes after AVNA occlusion and the AH interval was decreased from $89 \mathrm{~ms}$ to $75 \mathrm{~ms}$ (Figure 8, right panel).

\section{Discussion}

With inadequate oxygen supply to the myocardium, the adenosine levels in atrial and ventricular tissues are significantly elevated. ${ }^{18-20)}$ Belardinelli, et al reported adenosine as a possible candidate for biochemical mediation of the AV node conduction delay and block observed in hypoxic isolated rabbit and guinea pig hearts and in situ canine hearts. ${ }^{3,4,6)}$ Because the electrical activity of the nodal (N-zone) cells of the AV node is mainly dependent on "slow" $\mathrm{Ca}^{2+}-\mathrm{Na}^{+}$-mediated action potentials, ${ }^{21)}$ it is reasonable to assume that the $\mathrm{N}$-zone of the AV node is vulnerable to adenosine. The findings of the present study are consistent with previously reported findings that selective injection of adenosine in the AVNA rapidly produced a dose-dependent transient increase in the AH interval. ${ }^{6)}$ Dipyridamole potentiated the negative dromotropic effects of adenosine. The previously reported study also showed that intravenous administration of aminophylline, a competitive adenosine antagonist, attenuated the negative dromotropic effects of adenosine, and injection of theophylline into the AVNA rapidly reversed the AV block induced by AVNA occlusion with and without rapid atrial pacing.

Trapidil has been used in Japan since 1974 as an antianginal drug. Trapidil has also been shown to inhibit phosphodiesterase activity. ${ }^{12)}$ Thus, we hypothesized that trapidil would attenuate the negative dromotropic effects of adenosine. In the present study, we showed that trapidil attenuated the increase in $\mathrm{AH}$ interval induced by injection of adenosine into the AVNA and also reversed the second-degree AV block induced by injection of adenosine into the AVNA pretreated by dipyridamole, which was not affected by pretreatment with propranolol. Dipyridamole significantly increased and trapidil significantly decreased the $\mathrm{AH}$ interval. The previous report showed no significant changes in the AH interval by dipyridamole and aminophylline, ${ }^{6}$ but second-degree AV block developed in 3 of the 7 dogs given dipyridamole, and these 3 dogs were not included in the analysis. In addition, aminophylline was administered in only 3 dogs. Thus, the effects of dipyridamole and trapidil on the AH interval in the intact AV node require further investigation. We also showed that dipyridamole potentiated and trapidil attenuated prolongation of the $\mathrm{AH}$ interval induced by ischemia of the AV node region. Methylxanthines, such as theophylline and aminophylline, may exert their effects on the AH block induced by injection of adenosine into the AVNA or by ischemia by any of the following mechanisms: 1) translocation of intracellular calcium, 2) inhibition of phosphodiesterase leading to an increase in cyclic AMP, 3) release of catecholamines, and 4) blockade of adenosine receptors, and Belardinelli, et al surmised that the most likely mechanism by which theophylline reversed the effects of adenosine, hypoxia, and ischemia was its antiadenosine action. ${ }^{6)}$ The mechanism by which trapidil attenuates adenosine- and ischemia-induced $\mathrm{AH}$ prolongation needs further investigation. Clinical implications: Bradycardia, hypotension, and AV block are frequently observed in association with acute inferior myocardial infarction. ${ }^{22)}$ According to Adgey, et al bradycardia or AV block developed in $16 \%$ of patients seen within the first hour of onset of symptoms after posterior wall myocardial infarction. ${ }^{22)}$ Reversal of these bradyarrhythmias by atropine has led investigators to attribute the arrhythmias to an augmented vagal discharge. However, the efficacy of atropine in reversing the AV block appears to be influenced by the time after onset of symptoms at which the drug is administered. ${ }^{22)}$ The response to atropine in patients seen more than 8 hours after the onset of symptoms of myocardial infarction is very poor. ${ }^{22)}$ Hence, vagal hyperactivity may play an important role in the early phases of AV block accompanying inferior infarction. However, after several hours, a different mechanism may be operative. Local release of negative dromotropic substances and temporary hypoxia are thought to play a role, as shown in the previous $^{6}$ and present studies. In fact, several clinical reports have shown that both aminophylline and theophylline reverse atropine-resistant AV block during acute inferior myocardial infarction. ${ }^{23-28)}$ Thus, trapidil may also be effective in reversing atropine-resistant AV block during acute inferior myocardial 
infarction.

Study limitations: In the present study, the incidence of AV block induced by AVNA occlusion was low (14\%, 5/35 dogs). In a previously reported study, the incidence of AV block induced by AVNA occlusion was 23\% (5/22 dogs) without atrial pacing and $32 \%$ (7/22 dogs) with 20-30-minute rapid atrial pacing at 2.7-3.5 Hz. ${ }^{6}$ Thus, a longer ischemia time and rapid pacing might increase the incidence of ischemia-induced $\mathrm{AV}$ block. In addition, trapidil-mediated reversal of AV block during ischemia was by intravenous administration of the drug, and we did not investigate the effects of intracoronary injection. Thus, the decrease in aortic pressure achieved by intravenous administration of trapidil might affect AV nodal conduction.

\section{REFERENCES}

1. Drury AN, Szent-Györgyi A. The physiological activity of adenine compounds with especial reference to their action upon the mammalian heart. J Physiol 1929; 68: 213-37.

2. Stafford A. Potentiation of adenosine and the adenine nucleotides by dipyridamole. Br J Pharmacol Chemother 1966; 28: 218-27.

3. Belardinelli L, Fenton RA, West A, Linden J, Althaus JS, Berne RM. Extracellular action of adenosine and the antagonism by aminophylline on the atrioventricular conduction of isolated perfused guinea pig and rat hearts. Circ Res 1982; 51: 569-79.

4. Belardinelli L, Belloni FL, Rubio R, Berne RM. Atrioventricular conduction disturbances during hypoxia. Possible role of adenosine in rabbit and guinea pig heart. Circ Res 1980; 47: 684-91.

5. Senges J, Mizutani T, Pelzer D, Brachmann J, Sonnohof U, Kubler W. Effect of hypoxia on the sinoatrial node, atrium and atrioventricular node in the rabbit heart. Circ Res 1979; 44: 856-63.

6. Belardinelli L, Mattos EC, Berne RM. Evidence for adenosine mediation of atrioventricular block in the ischemic canine myocardium. J Clin Invest 1981; 68: 195-205.

7. Clemo HF, Belardinelli L. Effect of adenosine on atrioventricular conduction. I: Site and characterization of adenosine in the guinea pig atrioventricular node. Circ Res 1986; 59: 427-36.

8. Clemo HF, Belardinelli L. Effect of adenosine on atrioventricular conduction. II: Modulation of atrioventricular node transmission by adenosine in hypoxic isolated guinea pig hearts. Circ Res 1986; 59: 437-46.

9. Ohnishi H, Kosuzume H, Yamaguchi K, et al. Pharmacological properties of trapidil: comparison with other coronary vasodilators. Nippon Yakurigaku Zasshi 1980; 76: 495-503. (Japanese)

10. Takenaka F, Ishihara T, Hiraki I, Higuchi M, Ueda T, Nozaki M. Effect of 5-dimethyl-7-diethylamino-s-triazolo [1, 5-a] pyrimidine (trapymin, Rocornal) on cardiovascular system in the dog. Pharmacodynamics 1974; 8: 339-48.

11. Ito C, Yamaguchi K, Shichi S, et al. Effect of trapidil on the development of interarterial coronary anastomoses. Pharmacodynamics 1978; 16: 465-8.
12. Lampe D, Mai I, Busse E. The action mechanism of trapidil (Rocornal). Pharmazie 1975; 30: 807-8. (German)

13. Ohnishi H, Kosuzume H, Hayashi Y, Yamaguchi K, Suzuki Y, Itoh R. Effects of trapidil on thromboxane A2-induced aggregation of platelets, ischemic changes in heart and biosynthesis of thromboxane A2. Prostaglandins Med 1981; 6: 269-81.

14. Yamaguchi K, Suzuki K, Niho T, Sato M, Ito C, Ohnishi H. Reduction of myocardial infarct size by trapidil in anesthetized dogs. J Cardiovasc Pharmacol 1983; 5: 499-505.

15. Nadeau RA, Amir-Jahed AK. Selective perfusion of the AV node of the dog by cannulation of the posterior septal artery. Rev Can Biol 1965; 24: 291-7.

16. Scherlag BJ, Berbari EJ. Techniques for His bundle recordings. In: Narula OS, ed. His Bundle Electrocardiography and Clinical Electrophysiology. Philadelphia, Penn: FA Davis, 1975: 51-63.

17. Scherlag BJ, Abelleria JL, Samet P. Electrode catheter recording from the His bundle and left bundle in the intact dog. In: Kao FF, Koizumi K, Vassalle M, eds. Research in Physiology. Bologna, Italy: Aulo Gaggi, 1971: 223-38.

18. Thomas RA, Rubio R, Berne RM. Comparison of the adenine nucleotide metabolism of dog atrial and ventricular myocardium. J Moll Cell Cardiol 1975; 7: 115-23.

19. Rubio R, Berne RM. Release of adenosine by the normal myocardium in dogs and its relationship to the regulation of coronary resistance. Circ Res 1969; 25: 407-15.

20. Rubio R, Wiedmeier VT, Berne RM. Relationship between coronary flow and adenosine production and release. J Moll Cell Cardiol 1974; 6: 561-6.

21. Akiyama T, Fozzard HA. Ca and Na selectivity of the active membrane of rabbit AV nodal cells. Am J Physiol 1979; 236: C1-8.

22. Adgey AA, Geddes JS, Mulholland HG, Keegan DA, Pantridge JF. Incidence, significance, and management of early bradyarrhythmia complicating acute myocardial infarction. Lancet 1968; 2: 1097-101.

23. Wesley RC Jr, Lerman BB, DiMarco JP, Berne RM, Belardinelli L. Mechanism of atropine-resistant atrioventricular block during inferior myocardial infarction: possible role of adenosine. J Am Coll Cardiol 1986; 5: 1232-4.

24. Shah PK, Nalos P, Peter T. Atropine resistant post infarction complete AV block: possible role of adenosine and improvement with aminophylline. Am Heart J 1987; 113: 194-5.

25. Strasberg B, Bassevich R, Mager A, Kusniec J, Sagie A, Sclarovsky S. Effects of aminophylline on atrioventricular conduction in patients with late atrioventricular block during inferior wall acute myocardial infarction. Am J Cardiol 1991; 67: 527-8.

26. Goodfellow J, Walker PR. Reversal of atropine-resistant atrioventricular block with intravenous aminophylline in the early phase of inferior wall acute myocardial infarction following treatment with streptokinase. Eur Heart J 1995; 16: 862-5.

27. Bertolet BD, McMurtrie EB, Hill JA, Belardinelli L. Theophylline for the treatment of atrioventricular block after myocardial infarction. Ann Intern Med 1995; 123: 509-11.

28. Altun A, Kirdar C, Ozbay G. Effect of aminophylline in patients with atropine-resistant late advanced atrioventricular block during acute inferior myocardial infarction. Clin Cardiol 1998; 21: 75962. 